\title{
STEM in English for Early Childhood Ecological Awareness in China
}

\author{
Wenxiao Zhao' ${ }^{*}$ Shaoni Guo ${ }^{2}$ \\ ${ }^{1}$ School of Foreign Languages, University of Jinan, Jinan, CHINA \\ ${ }^{2}$ Chinesisch-Deutsche Technische Fakultaet, Qingdao University of Science and \\ Technology, Qingdao, CHINA \\ *Corresponding author:Sfl_zhaowx@ujn.edu.cn
}

\begin{abstract}
Changes in curricula, publication policy and information technology, notably in China have led to concentrations in the role of STEM (science, technology, engineering and mathematics) education in early childhood and applauded to proliferations of imported up-to-date reading materials and mobile apps in English. This paper proposes a longitude study of a Chinese toddler learning STEM by reading picture books and playing with tablet and suggests new horizons in parenting and in STEM education of ecological awareness during children's early years. The present study carried out from 2016, when the participant reached one year old, eligible to learn to speak and to concentrate on the picture books read by parents who had filled a language background questionnaire with information on themselves and the participant. Tablet playing brought about for the two-year-old toddler and collections of STEM books in English was added for the second year. Data collection lasted for two years with an iLab video camera, capturing utterances and motions for five minutes per week transcribed by VoiceScript software. Tests were given quarterly at private home by tapping in mobile app "Bilingual Child Learning" which consists of 20 basic STEM themes before scores were collected. Findings indicate that (1) it is accessible for children of very early years to be engaged in English STEM resources cultivating awareness of human impact on the environment and inspiring them to be a part of the solution, (2) kids' limited English dominance does not impede learning STEM, (3) and to think in English in early STEM contributes to children's English.
\end{abstract}

Keywords: STEM in English, early childhood ecological awareness, English picture books, Chinese toddlers

\section{INTRODUCTION}

\section{Background}

STEM research has incited theoretical concern in modern educational research. Early childhood exposure to STEM initiatives is a growing fixture in China. China has experienced a rapid current of change in its present academic curricula, its publication policy and information technology. These trends have led to a mass integration of science, technology, engineering, and mathematics (STEM). This research will explore a longitudinal study of STEM learning systems for toddler's awareness of ecology. This toddler-oriented system incorporates picture books and tablet games. This study was conducted in 2016, when participants reached one year of age. This child met criteria for speaking ability and capacity to focus on their attention on the pictures books. In the second year, STEM books tablets were added to the curriculum.
STEM education has dire implications in society, given the present economic and ecological trends. Mathematical and scientific skills render children competitive in the future economic climate (Langson et al. 2011). The future implications of these skills are salient given the current shifts in the professional realms. Professions centered on mathematics and science are growing in prominence, supplanting more traditional fields (Breiner et al. 2012). In fact, occupations in these fields are exceeding the growth of non-STEM oriented industries. The persistent growth of the global economy will ultimately hinge on those in these fields in question (Land 2013). Furthermore, in the future they may stabilize the economy and cater to its continued success. Hence, the STEM emphasis of this study's methods is imperative. These skills, when instilled at early ages, project future ecological awareness. The key is to inculcate these skills in early ages during impressionable developmental phases. This field of 
education is responsible for cultivating a host of critical skills (Stohlmann et al. 2012). It improves scientific capacity and critical thinking about the human impacts on the environment (Stohlmann et al. 2012). This also offers potential applications in nations where STEM skills are notably lacking.

The advent of technology has pervaded every realm of human life, and is re-defining professions. Furthermore, it is redefining education itself (Al Musawi 2011). These professions must integrate increasing awareness of technical skills to support the future. Engineering, an especially nuanced industry, however, addresses challenges relevant to the changing environment (Levenson 2011). Finally, mathematics pervades a multitude of studies in modern society. Furthermore, the landscape of education is transitioning to envelop all learners as proactive members of the learning process (Chen and Tseng 2012). This increasing engagement, and relative accessibility of learning tools and devices, may facilitate the transfer STEM knowledge. The preparation of environmentally friendly growth in these areas can commence at early stages.

\section{Rationale}

Findings support the conceptual idea that developmental views support early learning in children. Early opportunities and exposure to STEM will cultivate a desire and passion for those subjects. Developmental studies reveal neurogenesis occurs in the early stages of life. 7500 synaptic connection exist in the brain during birth (Mundkur 2005). However, in a period of 2 years, these neuron levels increase rapidly (Mundkur 2005). Hence the stage between infancy and 2-years of age is optimal for reinforcing STEM concepts. Neuroplasticity is far more vulnerable in the childhood mind. This refers to the physiological and structural changes in the brain as new synaptic connections form. These connections are formed in response to the reinforcement of skills (Mundkur 2005). However, neurogenesis is also a normal process. Adaptive plasticity occurs in the childhood brain and responds to specialization of skills. This process is expected to occur and support the implementation of the STEM curriculum teaching kids' awareness of ecology (Konedralı 2017).

\section{Problem Statement}

The problem statement for this study is as follows. This study seeks to explore the effect of STEM-related learning resources on infant/toddler aged children. It seeks to uncover which methods are conducive to quantitative learning in early stages and how those devices are employed to facilitate these outcomes (Tezer and Cumhur 2017).

\section{Research Questions and Hypothesis}

This study will incorporate the following hypothesis. Children, at early stages, may fully comprehend STEM concepts relative to their cognitive levels. It is also assumed that poor English proficiency will not impede STEM. Finally, students who think in English during STEM curriculums may amplify their English learning.

The following questions will be proposed in light of this study. How do picture books provide the critical precursors for high-order stem skills in children? Does second year STEM resources improve critical thinking about ecological awareness in toddler aged children?

\section{LITERATURE REVIEW}

A multitude studies have explored the early implementation of STEM-related concepts in children. In a study, conducted in the journal of Instructing Exceptional Children, a preschool teacher examined a STEM curriculum. Christa, the teacher, partook in a mixed-ability learning settings (Aronin and Floyd 2013). More specifically, she observed the impact of this method on a wide range of cognitive abilities, including children who suffered cognitive limitations. She centralized her focus on a fourstudent group, comprising students in the 4-year age range (Aronin and Floyd 2013). One student suffered from a developmental disorder. She instructed the child on learning new skills on the iPad tablet (Aronin and Floyd 2013). Each child awaited their turn as she instructed individuals on a new application. The iPad application was referred to as Monkey Math. Monkey Math is a STEM application tailored to children in early developmental stages (Aronin and Floyd 2013).

Another teacher featured in this study (Ms. Lena) is using a different application for her children (Aronin and Floyd 2013). She is instructing her students on engineering concepts with the aid of the BridgeBasher application. Student groups are devised to cultivate leadership and learning as well. Students show high levels of engagement in these classroom activities, hence the accessibility of STEM concepts (Aronin and Floyd 2013). As this study 
STEM in English for Early Childhood Ecological Awareness in China

conveys, there are many opportunities in preschool to cultivate STEM skills in early ages (Aronin and Floyd 2013). A number of devices and avenues may be used to facilitate this transfer of knowledge. Preschoolers have a host of opportunities to partake in technology (Aronin and Floyd 2013). This includes smart phones, computer labs, and education video games as well.

Some students, in light of learning these concepts, have suffered obstructions to their education process. Some technology is highly limited in terms of infusing concepts for preschool children (Aronin and Floyd 2013). Hence, in the study discussed for this paper, it is crucial to utilize accessible methods and technology. According to this study, the most effective methods entails targeting the youngest students, as they are more susceptible to novel concepts (Aronin and Floyd 2013). Hence, this vantage point justifies the study in discussion. Furthermore, results improve over long term stages, when technology is embedded in classroom settings. These designs are more effective when teachers and students partake in cooperative learning dynamics. The collective exchange of STEM knowledge is the best approach, as will be discussed (Aronin and Floyd 2013). Curriculums such as these were devised to improve students learning and bolster the entry into STEM careers (Aronin and Floyd 2013). This study teaches educators to optimize their use of available technology opportunities. Teachers should be wary of their interactions with children to preclude obstructions to STEM learning in childhood (Aronin and Floyd 2013).

Finally, this study emphasizes a few crucial principles to ensure the proper instruction of STEM concept (Aronin and Floyd 2013). First, the students should engage in the necessary action to ensure the anticipated outcomes. Students should be able to perceive the cause and effects of conceptual relationships by engaging in the necessary action and observing the ensuing outcomes (Aronin and Floyd 2013). The action and response should occur swiftly to ensure the child is properly conditioned.

Early exposure to STEM education alters student perceptions of learning. Perceptions often dictate motivation to learn in student environments. While STEM opportunities exist for high school and middle school students, fewer efforts are made for younger generations (DeJarnette 2012). Thus, STEM materials are especially lacking for toddlers and preschool aged children. Taking a proactive road to teaching STEM materials in earlier years forge true foundations for learning in high school (DeJarnette 2012). Slowly but surely, these initiatives have grown in prominence in the United States. Country comparisons were conducted in regards to the effects of STEM education on youth. A number of challenges exist in nations such as Australia in regards to implementation (Marginson et al. 2013).

The universal design for learning (UDL) can facilitate the employment of STEM learning materials. Teachers who improve their assessment strategies will enhance student outcomes (Basham and Marino 2013). Furthermore, efficacious instruction is also recommended to improve the STEM learning objectives (Basham and Marino 2013). This field provides opportunities for disabled students also to partake in math and science professions (Basham and Marino 2013).

STEM is also revealed to have experiential and creative potential as well. Some have petitioned adding the arts to the field to further integrated knowledge resources (Robelen 2011). It may be applied to the construction of technical toys designed for middle school children. However, this study provides no insight regarding applications to preschool children however (Quang et al. 2015). The technological field has been successfully instructed in middle schools in Vietnam (Quang et al. 2015). Technical toys can be devised in order to cultivate student competencies. Over the years, a rise in technical studies still remains controversial in the realm of education. However, toys provide a practical model of teaching students in modern educational environment (Quang et al. 2015). Using multidisciplinary perspectives, students can learn to apply these skills to the real world (Quang et al. 2015). This pertains to the study in questions which uses materials and tablet devices as well to emphasize STEM-related concepts. Such materials, which will be tested in this study, may facilitate instilling these skills in early childhood. These aforementioned studies pertain to the study being performed in this research. First, this research will utilize the integrative methods required for STEM oriented instruction (Becker and Park 2011). However, these findings will instead be adapted to serve the younger generation of preschool students. 
Perhaps, by beginning early, instructors can revise student perceptions of STEM knowledge.

A number of countries have grown to understand the economic value of STEM studies in school. These skills are absolutely imperative in the economic realm. Those who fail to embody these skills may fail to compete in the Turkish economy (Corlu et al. 2014). Modern criticisms have emerged regarding to critical reforms occurring in school environments (Corlu et al. 2014). Some contend teachers in this nation were neither equipped nor prepared to address these issues. Integrated teaching, however, can facilitate STEM instruction in school environments (Corlu et al. 2014).

However, the proper environment is required to ensure the implementation of this curriculum. A study assessed preschool environments to gauge their suitability for science education and learning (Brenneman 2011). The interest in preschool science is steadily increasing in the United States. Efforts have been made to bolster the science understanding and literacy in these environments as well (Brenneman 2011). This serves as a prerequisite to future, more intricate numerical and scientific concepts (Brenneman 2011). Notably, funding efforts in this area have increased in this area in order to support the employment of this model in the classroom. In spite of fundraising efforts, this has failed to yield a thorough integration of instructional methods. The issue is the implementation of STEM, which struggles to ensure lasting results in the United States (Brenneman 2011). New tools must be introduced to better assess child learning in science, along with instruction techniques for learning. Learning and knowledge assessments, entail sustaining and evaluating scientific learning (Brenneman 2011). This can be achieved with the aid of performance analyses. Furthermore, instruction should occur on an individualized basis for better results. To ensure the successful implementation of STEM concepts, it is crucial monitor progress as well (Brenneman 2011). Science learning thu requires more quality measures.

Modern studies support the notion that STEM education should commence during early childhood. STEM jobs are becoming increasingly difficult to find and secure in the global economy (Chesloff 2013). As noted, it is growing in competitiveness, hence the need for early childhood methods. This study, presented in this paper, proceeds along the notion of this issue, that early action yields sustainable results. When preschool children are exposed to these methods, they develop a host of skills to carry to the future. To deny these skills, in integrated settings, would create a significant economic drawback. Hence, this study should be viewed in longitudinal terms, rather than their immediate context in the study.

Additional studies have noted how assistive technology can reinforce STEM concepts in youth. Assistive technologies such as these were mimicked in the study in the form of a tablet device (Clabaugh et al. 2015). However, other studies have explored the realm of robotic technology to aid this potent educational climate. Socially Assistive Robot tutoring systems were observed in a STEM study (Clabaugh et al. 2015). It was determined this technology could inculcate favorable learning behaviors and patterns as well. Therefore technology is integral to instilling the desired behaviors conducive to scientific and numerical knowledge. Other studies have confirmed the overall effectiveness of touchscreen technology for preschool STEM learning knowledge (Aladé et al. 2016). Computer based scaffolding can also aid students as they strive to utilize STEM-oriented skills.

\section{METHODOLOGY AND DESIGN}

The methodology of this study is presented as follows. The design will entail a longitudinal method of STEM instruction, via picture books and tablet technology. Data collection will ensue over a period of two years. The materials for this study encompassed an iLab video camera, recording motions and utterances five minutes per week. Responses were transcribed and recorded with the aid of VoiceScript software. Confederates performed tests at quarterly intervals in home environments by partaking in the mobile app. Bilingual Child Learning comprised a total of 20 STEM themes after which scores were obtained (Sturgeon 2018).

The study was first performed in 2016 when the participants reached one year old. They were capable of speaking and concentrating focus on the picture books employed. The parents fulfilled the language criteria by completing an assigned questionnaire, in which they recorded personal data. At one year of age, children were provided picture books to 
STEM in English for Early Childhood Ecological Awareness in China

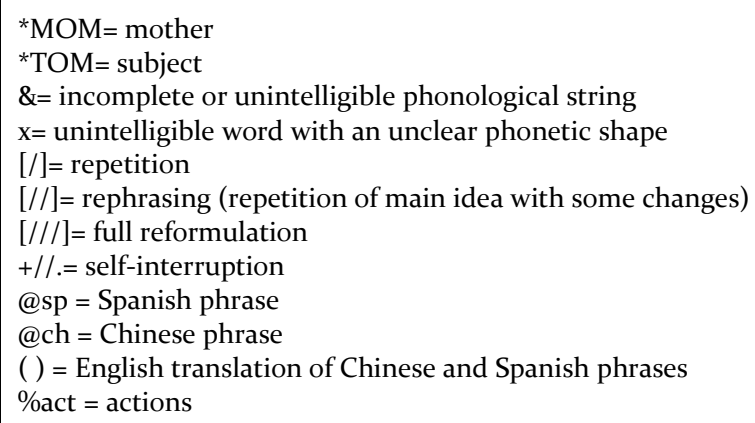

Fig. 1.Transcription conventions

stimulate STEM conceptual learning. At age two, the toddlers were provided a tablet and a compilation of STEM books. All books were accessible to children during early ages, and their English proficiency did not affect STEM comprehension.

This study implemented the following procedure. A coding mechanism was used to encode the subject responses (Fig. 1). MOM signified mother, and TOM signified the subject of the study. The symbol " $\&$ " refers to incomplete or unintelligible phonological strings. The " $x$ " symbol signifies unintelligible words with unclear phonetic shapes. [/] signifies repetition, [//] signifies rephrasing, [///] symbolizes full reformulation, +// symbolizes self-interruption, @sp, Spanish phrase, @ch, a Chinese phrase, ( ) = English translation of Chinese and Spanish phrases, \%act signifies actions.

The study encompassed distinct concepts for each learning trial. The first context pertained to "Drawing with oval shaped bicolor crayons". The duration was 5 minutes. This was labeled as Transcription o1 "colors". The second context, which persisted for 4 minutes, was "In the kitchenette designed for children with plastic fruit and vegetables." This was labeled as Transcription 02, Fruit and Vegetables. The third context resided "In the kitchen designed for children with plastic fruit and vegetables." This was labeled Transcription 03 "Healthy Food". The duration was 4 minutes long. Transcription 04, or "Counting Animals" entailed the following context "Playing with toy animals after lunch." the duration was 4 minutes long. Transcription 05, or "Plus and Minus" incorporates the context "playing before sleep". The duration of this study was 5 minutes long.

\section{RESULTS}

The results of this study indicated the following results. The Transcription or results uncovered the following findings (Appendix A). In this trial, the child is asked to identify a color and correctly responds it is orange, in Chinese. The child was asked to pronounce the word in English as well, to which the child responded correctly. The mother responded with an interrogative remark, to inquire if the color is orange, which the child confirms. The child was asked if orange was the only color present in this context. He notes that green is present in Chinese. The mother responded and stated it was green in English, then awaited the physical action of the child. The child gestured to the green side. This implied the child comprehended "green" in English. The child then rephrased and repeated the term "green". The mother then instructed the child to remember the color was phrased "green". The child intimated understanding by nodding his head. The mother instructed the child to point to the blue and red crayon/ The child inquired which crayons met this criteria and the mother gestured to the correct color. The child then pointed the side, and used an interrogative marker for "blue" in Chinese. The mother asked the child to vocalize blue in English and to name the additional crayon in English, which was red. The child employed repetition and rephrasing to name the crayons "red" and "blue" in English. The child is presented an upside down dual colored crayon. The child was asked to point to the red side. The child inquired if a given side is yellow and gestured in that direction. The child gestured to the purple side of a crayon, and requested the name of this color. The mom responded the color was "purple" to which the child responded "bubble". The child made a connection between purple and grape to distinguish it from bubble. This revealed conceptual and practical knowledge, relating an attribute to the real world. The child pointed to the pink side of the crayon and inquired if it was orange, incorrectly. The mother confirmed it was not orange. The child used repetition to inquire if the color was red, which was also incorrect. The mother revealed it was pink and requested the child ponder explaining the pink color. The mother conveyed the Chinese translation equated to powdered red. The child used an interrogative marker to confirm the pink color was in fact powdered red in Chinese. The child noted a particular visual was pink and black. The mother confirmed the visual was pink and black. The child employed repetition and re-affirmed these color names. 
The results of Transcription 02 revealed the following findings (Appendix A). The instructor enabled the child to distinguish between fruit and vegetables in order to inspiring him to be a part of the solution of ecology. This was achieved through rephrasing on the part of the instructor. The child used interrogative reasoning to determine if apple and banana were fruit. The child was instructed to identify more fruit. These fruits included pear, grape, and peach. The aforementioned fruits were identified in English. However, the child struggled to identify papaya. The child was informed the unknown fruit was a papaya and instructed to point in its direction. The subject then identified papaya in Chinese by name. This child also vocalized water melon in Chinese. The child then inquired if watermelon is a fruit, to which the instructor responded yes. The instructor asked the child to identify an unknown vegetable. The child pointed in the direction of the potato. The child struggled to enunciate the word "potato". An interrogative marker was used to distinguish the pronunciation between potato in english and Chinese, by the subject. When the child is asked is he/she likes potatoes, this is followed by silence. This implies a lack of understanding of the question. The child is asked if it is fruit or vegetable, and responds it is a vegetable.

The results of Transcription 03 revealed the following findings (Appendix A). The mother asked the subject to identify awareness of healthy food, after which the child gestured toward an apple. The mother proceeded to inquire of another healthy food, after which the child gestured to a carrot. The mother revealed chocolate to assess the child's differentiation between healthy and unhealthy food. The child responded with yes, followed by rephrasing with "no". The mother confirmed this response, and associated "no" with the wiggle of the left index finger. The mother proceeded to permit a small piece of chocolate per day. After splitting a piece and passing it to Thomas, she reinforced the rule of unhealthy food. For further reinforcement, she inquired of the daily frequency child was permitted to consume chocolate. The child is asked if lollipops are healthy, to which the mother responds with no.

The results of Transcription 04 revealed the following findings (Appendix A). In this context, the child distinguished among one, two, and three and completed basic addition (one plus one). The child identified an imitation elephant by abridging its name to Eli. The mother requested the full name of the animal, to which the child responded "Elephant". The mother placed three flashcards of elephants together and inquired how many were present, presenting the problem what is "one plus two". The child initially responded with two, showing limitations in quantitative reasoning (normal for this age). The mother requested the child count the present elephants to reinforce the mathematical equation, to which the child responded three. The mother proceeded to reinforce the numerical value of one plus two. The mother introduced the child to the next animal, which the child identified as a cat. She requested the child identify the number of cats by inquiring what is "two plus two", placing four cards together. The child responded incorrectly with "three" after which they proceeded to count the individual cards. After reinforcement, the child answered four.

The results of Transcription o5 revealed the following findings (Appendix A). This trial uncovered the child's quantitative reasoning. The child calculated one plus four correctly. The child also demonstrated the capacity for subtraction. The child demonstrated these qualities by gesturing toward books.

\section{CONCLUSION, DISCUSSION, AND RECOMMENDATIONS}

The following findings were uncovered, as per the hypothesis. This study determined that early age toddlers were capable of assimilating STEM knowledge and thinking critically about environment and daily life. Children demonstrate conceptual faculties which enable this process, and assures the transfer of STEM knowledge. This study also confirmed the ease of transmission this knowledge, in spite of linguistic barriers. Early childhood toddlers were capable of making complex conceptual connections. In Transcription 03, a child was asked to identify an ecologically healthy food, and responded by selecting an apple. This implies children inculcate knowledge of nuanced ideas (e.g. healthy), the cause-and-effect impact on the human body, and how those results are achieved. This cause and effect knowledge forms the basic foundations of empirical thought. Empirical thought, of course, guides STEM knowledge. 
STEM in English for Early Childhood Ecological Awareness in China

In addition to visual recognition, and conceptual dynamics, this study examined quantitative reasoning. Using a visual appeal, the confederate in the study reinforced quantitative knowledge in the subject. This implies both visual and technological tools, suited for early development toddlers, can inculcate STEM knowledge in early stages. Quantitative reasoning can be achieved in ways accessible to toddlers. Technology and visual aids can stimulate comprehension when embedded in the proper format. The study also compels one to reconsider traditional teaching roles. Firstly, parents can initiate the transfer of STEM concepts through technological means. Accordingly, learning and cultivate environmentally friendly awareness of is more than a passive process, but rather, a collective and interactive one.
A few limitations arose in the course of this study. The study results are not generalizable to populations. The sample size was too small to account for cognitive trends in the general population. In order to reproduce these trends, and verify the generalizable effective of these methods, a large sample size is needed in the future. Another limitation is the lack of definable variable and empirical measures of that variable.

This has massive implications for future studies in regards to STEM knowledge and ecological awareness for early developmental stages. Researchers can utilize these findings to facilitate the science and ecological gaps. Mitigating this gap in early developmental years, can bypass discrepancies in the future.

\section{REFERENCES}

Al Musawi AS (2011) Redefining technology role in education. Creative Education, 2(2): 130-135.

Aladé F, Lauricella AR, Beaudoin-Ryan L, Wartella E (2016) Measuring with Murray: Touchscreen technology and preschoolers' STEM learning. Computers in Human Behavior, 62, 433-441.

Aronin S, Floyd KK (2013) Using an iPad in inclusive preschool classrooms to introduce STEM concepts. $\begin{array}{llll}\text { Teaching } & \text { Exceptional } & \text { 35ildren, } & \text { 45), }\end{array}$ https://www.researchgate.net/publication/259383269 Ms Using an iPad in Inclusive Preschool Classrooms to Introduce STEM Concepts

Becker K, Park K (2011) Effects of integrative approaches among science, technology, engineering, and mathematics (STEM) subjects on students' learning: A preliminary meta-analysis. Journal of STEM Education: Innovations and Research, 12(5/6), 23.

Belland BR, Walker AE, Kim NJ, Lefler M (2017) Synthesizing results from empirical research on computerbased scaffolding in STEM education: A meta-analysis. Review of Educational Research, 87(2): 309-344.

Breiner JM, Harkness SS, Johnson CC, Koehler CM (2012) What is STEM? A discussion about conceptions of STEM in education and partnerships. School Science and Mathematics, 112(1): 3-11.

Brenneman K (2011) Assessment for Preschool Science Learning and Learning Environments. Early Childhood Research \& Practice, 13(1): 55-74.

Chen HR, Tseng HF (2012) Factors that influence acceptance of web-based e-learning systems for the inservice education of junior high school teachers in Taiwan. Evaluation and program planning, 35(3): 406.

Chesloff JD (2013) STEM education must start in early childhood. Education Week, 32(23): 27-32.

Clabaugh C, Ragusa G, Sha F, Matarić M (2015) Designing a socially assistive robot for personalized number concepts learning in preschool children. In Development and Learning and Epigenetic Robotics (ICDLEpiRob), 2015 Joint IEEE International Conference on IEEE (pp. 314-319).

Corlu MS, Capraro RM, Capraro MM (2014) Introducing STEM education: implications for educating our teachers for the age of innovation. Egitim ve Bilim, 39(171).

DeJarnette N (2012) America's children: Providing early exposure to STEM (science, technology, engineering and math) initiatives. Education, 133(1): 77-84. https://www.researchgate.net/profile/Nancy Dejarnette/ publication/281065932 America\%27s Children Providing early exposure to STEM Science Technolo gy Engineering Math Initiatives/links/56e8ao1208ae166360e52647/Americas-Children-Providing-earlyexposure-to-STEM-Science-Technology-Engineering-Math-Initiatives.pdf

Konedralı G (2017) Effects of a Programmed Turkish Grammar Instruction on Students' Language Skills. Eurasia Journal of Mathematics, Science and Technology Education, 13(11): 7539-7547. 
Land MH (2013) Full STEAM ahead: The benefits of integrating the arts into STEM. Procedia Computer Science, 20: 547-552.

Langdon D, McKittrick G, Beede D, Khan B, Doms M (2011) STEM: Good Jobs Now and for the Future. ESA Issue Brief\# 03-11. US Department of Commerce.

Leveson N (2011) Engineering a safer world: Systems thinking applied to safety. MIT press.

Marginson S, Tytler R, Freeman B, Roberts K (2013) STEM: country comparisons: international comparisons of science, technology, engineering and mathematics (STEM) education. Final report.

Mundkur N (2005) Neuroplasticity in Children. Indian Journal of Pediatrics. 72: 105-131.

Quang LX, Hoang LH, Chuan VD, Nam NH, Anh NTT, Nhung VTH (2015) Integrated Science, Technology, Engineering and Mathematics (STEM) Education through Active Experience of Designing Technical Toys in Vietnamese Schools. arXiv preprint arXiv:1509.03807.

Robelen EW (2011) STEAM: Experts make case for adding arts to STEM. Education week, 31(13): 8-17.

Stohlmann M, Moore TJ, Roehrig GH (2012) Considerations for teaching integrated STEM education. Journal of Pre-College Engineering Education Research (J-PEER), 2(1): 4-22.

Sturgeon A (2018) Why Literacy Should be Included in an Effective Elementary Math Curriculum. Eurasia Journal of Mathematics, Science and Technology Education, 14(2): 557-56o.

Tezer M, Cumhur M (2017) Mathematics through the ${ }_{5} \mathrm{E}$ Instructional Model and Mathematical Modelling: The Geometrical Objects. Eurasia Journal of Mathematics, Science and Technology Education, 13(8): 4789-4804. 
STEM in English for Early Childhood Ecological Awareness in China

APPENDIX A

Transcription o1: Colors

\begin{tabular}{|c|c|}
\hline Context & Drawing with oval shaped bicolor crayons \\
\hline Time & o6/o1/2018 afternoon \\
\hline Duration & 5 minutes \\
\hline *MOM: & okay, what's the color? \\
\hline *TOM: & Chengse@ch (orange). \\
\hline${ }^{*} \mathrm{MOM}:$ & chengse@ch (orange) yingyu@ch (English) jiao@ch (Call) shenme@ch (what) \\
\hline *TOM: & orange \\
\hline *MOM: & orange? \\
\hline *TOM: & Orange! Orange! \\
\hline${ }^{*} \mathrm{MOM}:$ & YES, orange, very good. \\
\hline *MOM: & And, only orange? \\
\hline *TOM: & hai@ch (still) you@ch (have) lvse@ch (green). \\
\hline *MOM: & lvse@ch (green), in English? \\
\hline \%act: & point to the green side of the crayon \\
\hline *TOM: & It [//] it's g\& [/] g\&, green. \\
\hline *MOM: & this is green, right. \\
\hline${ }^{*} \mathrm{MOM}:$ & Remember! yingyu@ch (English) jiao@ch (call) green. \\
\hline *TOM: & Ah. \\
\hline \%act: & Nod his head. \\
\hline *MOM: & right then how_about this crayon? \\
\hline \%act: & point to the blue and red crayon. \\
\hline *TOM: & Nayige@ch (which one) \\
\hline *MOM: & This one, this one. \\
\hline \%act: & point to the blue side. \\
\hline *TOM: & Lanse@ch (blue) de@ch (of) ma?@ch (interrogative marker) \\
\hline * MOM: & In English. \\
\hline *TOM: & Blue. \\
\hline * MOM: & Blue and ? \\
\hline *TOM: & $<$ Blue and $>[/]<$ Blue and $>[/ /]$ Blue and red \\
\hline \%act: & Upside down the oval shaped bicolor crayon \\
\hline \%act: & point to the red side \\
\hline *MOM: & Yes, good job. \\
\hline *TOM: & huangse@ch (yellow) shi@ch (be) yellow ma?@ch (interrogative marker) \\
\hline \%act: & point to the yellow side of another crayon \\
\hline *MOM: & Yes, it's yellow. \\
\hline *TOM: & Eh... \\
\hline *TOM: & Zhege@ch (this) jiao@ch (call) shenme@ch (what) \\
\hline \%act: & point to the purple side of another crayon \\
\hline *MOM: & Purple \\
\hline *TOM: & Bubble? \\
\hline *MOM: & Not water bubble for bath, it's pur-ple \\
\hline *TOM: & Purple grape? \\
\hline${ }^{*} \mathrm{MOM}:$ & Yeah! Purple grape \\
\hline *TOM: & orange too? \\
\hline \%act: & point to the pink side of another crayon \\
\hline *MOM: & It's not orange. \\
\hline *TOM: & Red [/] hongse@ch (red)? \\
\hline *MOM: & It's not so red [//] it's a little red [//] it's pink \\
\hline \%act: & Think about how to explain the pink color \\
\hline *TOM: & Pink shi@ch (shi) shenme@ch (shenme) yanse@ch (color) \\
\hline *MOM: & shi@ch (be) fenhong@ch (pink, literally it means “powdered red”) se@ch (color) \\
\hline * EDW: & fenhongse@ch (powdered red color) jiushi@ch (be) pink ma?@ch (interrogative marker) \\
\hline${ }^{*} \mathrm{MOM}:$ & Yes, Thomas. \\
\hline *TOM: & Eh, it's pink and [/] and [/] black. \\
\hline *MOM: & Great! Clap for Thomas! \\
\hline \%act: & Clap hands \\
\hline *TOM: & Eh. \\
\hline \%act: & Smile with teeth and run quickly to find toys. \\
\hline
\end{tabular}


Zhao

Transcription o2: Fruit and Vegetables

\begin{tabular}{|c|c|}
\hline Context & In the kitchenette designed for children with plastic fruit and vegetables \\
\hline Time & 10/o1/2018 morning \\
\hline Duration & 4 minutes \\
\hline *TOM: & fruit is vegetable? \\
\hline *MOM: & Well, no, fruit is fruit and vegetable $+/ /$ is vegetable \\
\hline \%act: & Apple in the left hand and cabbage in the right hand \\
\hline *TOM: & apple is fruit? \\
\hline \%act: & Take the plastic apple from mother's hand \\
\hline *MOM: & Yeah, apple is fruit \\
\hline *MOM: & And more fruit? \\
\hline *TOM: & Banana is fruit? \\
\hline \%act: & take a banana from the basket \\
\hline *MOM: & Yes, it is and find more fruit. \\
\hline *TOM: & Pear, grape, peach and zhege@ch (this one) jiao@ch (call) shenme@ch (what) \\
\hline *MOM: & Papaya. \\
\hline \%act: & point to the plastic fruit which seems to be a papaya \\
\hline *TOM: & Papaya zhongwen@ch (in Chinese) shi@ch (be) shenme@ch (what) \\
\hline *MOM: & mugua@ch (papaya, literally it means “wooden melon” ) \\
\hline *TOM: & Na@ch (then) xigua@ch (watermelon, literally it means “west melon”) yingyu@ch (in English) jiao@ch (call) shenme@ch (what) \\
\hline *MOM: & Watermelon. \\
\hline *TOM: & Shui@ch (water) gua@ch (melon)? \\
\hline *MOM: & Yes, watermelon is melon of water. Limian@ch (inside) you@ch (have) xuduo@ch (a lot of) shui@ch (wather) \\
\hline *TOM: & Waterlemon is fruit? \\
\hline *MOM: & Yes, of course. \\
\hline *MOM: & And What's this? \\
\hline \%act: & Point to the potato \\
\hline *TOM: & patata@sp (potato) \\
\hline *MOM: & Sí@sp (yes), ¿en@sp (in) inglés@sp (English)? \\
\hline *TOM: & Pa\& pa\& p\& \\
\hline *MOM: & Po-ta-to. \\
\hline *TOM: & Potato shi@ch (shi) yingyu@ch (English) ma?@ch (interrogative marker) \\
\hline *MOM: & Yes, so Potato in English, Patata@sp (Potato) en@sp (in) inglés@sp (English), zhongwen@ch (Chinese) jiao@ch (call) shenme@ch (what) \\
\hline *TOM: & Tudou@ch (potato) \\
\hline *MOM: & Do you like potatos? \\
\hline *TOM: & $\ldots$ \\
\hline \%act: & Keep silent, it seems he doesn't understand the question. \\
\hline *MOM: & Te@sp (to you), gustan@sp (like), patatas@sp (potatos)? (This spanish sentence menas “do you like potatos”. ) \\
\hline *TOM: & Sí@sp (yes) \\
\hline *MOM: & Thomas, is it fruit or vegetable? \\
\hline *TOM: & Vege\& \\
\hline \%act: & Try to find other items in the basket \\
\hline
\end{tabular}


STEM in English for Early Childhood Ecological Awareness in China

Transcription o3: Healthy Food

\begin{tabular}{|c|c|}
\hline Context & In the kitchenette designed for children with plastic fruit and vegetables \\
\hline Time & 10/o1/2018 morning \\
\hline Duration & 4 minutes \\
\hline *MOM: & Thomas, find one food that is healthy for us. \\
\hline *TOM: & Apple? \\
\hline \%act: & Grab an apple in his right hand \\
\hline *MOM: & And more healthy food. \\
\hline *TOM: & This. \\
\hline *MOM: & Is carrot healthy food? \\
\hline *TOM: & Eh. \\
\hline *MOM: & Ok. And, is this healthy food? \\
\hline \%act: & Take out a bar of chocolate from the pocket \\
\hline *TOM: & $\begin{array}{l}\text { Yes+//. No, No, No.wo@ch (I) yao@ch (want) chi@ch (eat) qiaokeli@ch (chocolate) [/]wo@ch (I) yao@ch (want) } \\
\text { chi@ch (eat) qiaokeli@ch (chocolate) [/]wo@ch (I) yao@ch (want) chi@ch (eat) qiaokeli@ch (chocolate) }\end{array}$ \\
\hline *MOM: & Chocolate is not healthy, not good. \\
\hline \%act: & Wiggle left index finger to show the meaning of "no" \\
\hline *TOM: & $\begin{array}{l}\text { wo@ch (I) yao@ch (want) chi@ch (eat) qiaokeli@ch (chocolate) [/]wo@ch (I) yao@ch (want) chi@ch (eat) qiaokeli@ch } \\
\text { (chocolate) [/]wo@ch (I) yao@ch (want) chi@ch (eat) qiaokeli@ch (chocolate) } \\
\end{array}$ \\
\hline \%act: & Tend to cry \\
\hline *MOM: & So only one chocolate a day, okay? \\
\hline \%act: & Split a little piece of chocolate and pass it to Thomas \\
\hline *MOM: & So, how many time a day? \\
\hline *TOM: & ... \\
\hline \%act: & Show his right index finger to express the number "one" \\
\hline *MOM: & So, how many time a day? \\
\hline *TOM: & One. No, two! \\
\hline *MOM: & One! \\
\hline *TOM: & Okay, one. Dangao@ch (cake) ne? @ch (interrogative marker) \\
\hline *MOM: & One cake a day \\
\hline *TOM: & Lollipop? \\
\hline *MOM: & No lollipops. \\
\hline *TOM: & You@ch (have) [/] You@ch (have), bingxinag@ch (refrigerator) limian@ch (inside) you@ch (have) \\
\hline *MOM: & Is lollipop healthy food? Is lollipop good? \\
\hline \%act: & Thumb up \\
\hline *TOM: & Not good \\
\hline *MOM: & So one lollipop a week. \\
\hline *TOM: & Yi@ch (one) zhou@ch (week) yi@ch (one) ge@ch (item) ma?@ch (interrogative marker) \\
\hline *MOM: & Yes, one week. \\
\hline
\end{tabular}


Zhao

Transcription o4: Counting Animals

\begin{tabular}{|c|c|}
\hline Context & Playing with toy animals after lunch \\
\hline Time & $5 / 02 / 2018$ afternoon \\
\hline Duration & 4 minutes \\
\hline *MOM: & One two and? \\
\hline *TOM: & Three. \\
\hline *MOM: & Ok, so next question, one.... \\
\hline \%act: & Index finger form one \\
\hline *MOM: & one plus one? \\
\hline *TOM: & two. \\
\hline *MOM: & what's this animal? \\
\hline *TOM: & Eli. (Elephant, an imitation of the cartoon titled Pocoyo) \\
\hline *MOM: & Full name. \\
\hline *TOM: & Elephant. \\
\hline *MOM: & right, one plus two ? how many elephants right now? \\
\hline \%act: & Put three flashcard together \\
\hline *TOM: & Two. \\
\hline *MOM: & one plus two, look. \\
\hline \%act: & Show one figure with left hand and two fingers with the right hand \\
\hline *TOM: & Dengyu@ch (equal to) san@ch (three) ma?@ch (interrogative marker) \\
\hline *MOM: & Yes. So one plus two is? \\
\hline *TOM: & Three. \\
\hline *MOM: & Ok what's the next, which animal? Moew, Moew \\
\hline *TOM: & Cat moew. \\
\hline *MOM: & Yes. \\
\hline *MOM: & So how many moew moew cats can you see? \\
\hline \%act: & Show four flashcards of cats. Two cards with left hand and two with right hand \\
\hline *MOM: & Two plus two? \\
\hline *TOM: & Three. \\
\hline *MOM: & Let's count, one, two, three, four. How many? \\
\hline *TOM: & Meow, Meow, Meow, Meow. \\
\hline *MOM: & So how many meows? \\
\hline *TOM: & Sige@ch (four items). \\
\hline *MOM: & what's the animal ? \\
\hline *TOM: & ... \\
\hline \%act: & Wiggle his head \\
\hline *MOM: & Oh, John the ra\& (lyric of a kid song "John the Rabbit") \\
\hline *TOM: & Ra\&, Ra\&, Rabbit. \\
\hline *MOM: & Great. How many rabbits? \\
\hline *TOM: & Xiao@ch (little) tuizi@ch (rabbit) yao@ch (will) shuijiao@ch (go to sleep) le@ch (accomplishment aspectual marker) \\
\hline \%act: & Run quickly to another room. \\
\hline
\end{tabular}


STEM in English for Early Childhood Ecological Awareness in China

Transcription o5: Plus and Minus

\begin{tabular}{|c|c|}
\hline Context & Playing before sleep \\
\hline Time & 8/o2/2018 night \\
\hline Duration & 5 minutes \\
\hline *MOM: & Thomas, one plus three? \\
\hline *TOM: & one y@sp (and) three, four. \\
\hline *TOM: & Sí@sp (yes)? \\
\hline \%act: & point to himself \\
\hline *MOM: & Yes ,it's four. Very good. \\
\hline *MOM: & And I have two books and you have two books. How many books now? \\
\hline *TOM: & Mama@ch (mother) you@ch (have) liangge@ch (two items), wo@ch (I) you@ch (have) liangge@ch (two items). \\
\hline \%act: & Try to count with fingers but fail to find solution \\
\hline *MOM: & So how many books? \\
\hline *TOM: & No. \\
\hline \%act: & Wiggle his head \\
\hline *MOM: & Look, one book, two books, three books and? \\
\hline \%act: & show four small picture books \\
\hline *TOM: & siben@ch (four) shu@ch (books) \\
\hline *MOM: & Yes, in English? \\
\hline *TOM: & Four ks\& [//] four books. \\
\hline *MOM: & So I take one book away, how many left now? \\
\hline \%act: & Take a book and place it behind her \\
\hline *TOM: & One, two, three. \\
\hline *MOM: & So how many? \\
\hline \%act: & Point to the tree books on the table \\
\hline *TOM: & Three. \\
\hline *MOM: & Then four minus one is? \\
\hline \%act: & Point to the tree books on the table \\
\hline *TOM: & Three. \\
\hline *MOM: & Then three minus one? \\
\hline \%act: & Take a book and place it behind her \\
\hline *TOM: & One two. And two. \\
\hline *MOM: & Ok, then two minus one? \\
\hline \%act: & Point to the only book left on the table \\
\hline *TOM: & Mama@ch (mother) Zhi@ch (only) sheng@ch (leave) yiben@ch (one volume) le@ch (accomplishment aspectual marker) \\
\hline \%act: & Show kind of afraid of the reduction of number \\
\hline
\end{tabular}

